Ontology and Social Relations: reply to Doug Porpora and to Colin Wight

Tony Lawson

University of Cambridge

Author Note

Tony Lawson, Faculty of Economics, University of Cambridge

Correspondence concerning this article should be addressed to Tony Lawson, Faculty of Economics, University of Cambridge, Cambridge CB3 9DD, UK

Tony.Lawson@econ.cam.ac.uk 


\section{Ontology and Social Relations: reply to Doug Porpora and to Colin Wight ${ }^{1}$}

I am pleased to be debating here with Doug Porpora and Colin Wight, something I am more used to doing over a glass or two than in print (actually the same is true re John Searle, though it is a less frequent occurrence). This move to a more public forum has led to Porpora's and Wight's excellent critical commentaries, and I am grateful. But it does not seem to have stopped them seeking to provoke through attributing labels they know full well are very far from any I might accept. Here I rise to their provocation.

At the heart of their interventions is a shared concern that the conception I defend prioritises a certain form of social relation, constituted through matched rights and obligations, a form they deem to be either insufficiently material or conflictual, or overly subjective or socialised.

It is certainly the case that features like rights and obligations may themselves be, in part, mind-dependent, being either the material (remembered) outcomes of previous decision making processes including declarations, or, and I suspect more frequently, emergent components of material collective practices. But whatever the case, they are always not only exercised by, but emergent from, and remaining dependent upon, material human beings participating in their equally material inter- and intra-actions, and so cannot reasonably be considered as other than features of an emergent powers materialism (see Lawson, 2012); there is nothing immaterialist in any of this.

This, though, does not obviate the fact that Porpora and Wight remain unhappy with my specific relational emphasis. Seemingly inferring that this emphasis means that the conception I defend is unable, as it stands, to accommodate other forms, or significant features, of social relations, Porpora and Wight find it deficient. At one point, Porpora suggests that "power over in any of its manifestations cannot be accommodated by Lawson's ontology" (Porpora, 2016, p. 9). This might be interpreted as a rejection of the content of the 
ontology. Most of the time, though, Porpora makes it clear that he supposes that the conception I defend (as indeed with Searle's) is merely limited in scope and "In principle, $[\ldots]$ could be augmented to accommodate the stronger more materialist view of social structure" (ibid, p. 4) to which Porpora himself subscribes, presumably including 'powerover' relations.

This is a fairly constructive and friendly line of criticism, and, if I understand it correctly, quite restrained in that these authors nowhere suggest that, beyond limiting coverage, the conception I defend leads to actual error. So I feel somewhat churlish in nevertheless opposing it.

Yet I should. For whilst the conception I defend is hardly limited to accommodating relations of the positional rights-obligation sort (though I do regard the latter as fundamental), I am not convinced anyway that most of the forms of relations or relational features that Porpora and Wight put forward as alternative are actually any such thing. It is the latter set of issues that I suspect are the more interesting to discuss here; so I start out focusing on them, turning to the broader coverage of the ontological framework I defend only briefly towards the end.

\section{Power relations}

I consider first some examples of supposed alternative relations or features provided early on by Porpora. Adopting the perspective of a third social ontology group, Porpora focuses on structure, suggesting that this is something:

“[...] which like Lawson we generally [...] consider to be social relations but which, unlike Lawson, we do not confine to relations defined by subjectively recognised rights and obligations; instead we extend structure to extra-discursive relations like power over, inequality, exploitation and conflicts of interest" (ibid, p. 3, italics in the original). 
As I say, I turn to broader issues like the claim that I "confine" all relations to those constituted by matching recognised rights and obligations in due course. At this point I want to examine the suggestion that the relations noted by Porpora somehow represent forms that lie beyond the positional rights-obligations relation that is central to the conception I defend. Consider first the power over relation. In fact, the feature of conferring 'power over' is, I suggest, the very essence of a right-obligation positional relationship. Where a right is attached to one position a matching obligation is also attached somewhere, usually to a different (set of) position(s). It is through the mechanism of exercising a positional right that a right-bearer can get a corresponding obligation-bearer to do various things whether or not the latter cares to. As a university lecturer I have the right to request a book kept in the basement of my Faculty library (a basement that only library staff are able to access). If I exercise that right, then someone else has the obligation to go fetch it even if it is the last thing in the world he or she wants to do. This is the nub of all 'power over' relations: the ability to get others to do what is wanted of them irrespective of the desires of these others.

Of course, the physical ability to so act, the powers of efficient causation invoked in any exercise of deontic/positional power, say in requesting a book, or in fetching the book from the basement, relate to capacities possessed by individuals independently of their occupying the relevant positions. That, in part, is why I insist against Searle that all positions have at least one occupant, that there are no 'free standing Y terms'.

I do not suggest that all 'power over' relations are of this rights-obligations sort (though I strongly suspect most of the ontologically interesting ones are -- an issue to which I return below). But I do maintain that all rights-obligation relations are of this 'power over' sort. I certainly think Porpora is not quite right to suppose that: "[...] power over in any of its manifestations cannot be accommodated by Lawson's ontology" 


\section{Exploitation}

Porpora also talks of relations of exploitation. This is an example that, far from being at odds with the conception of rights-obligation relations I defend, serves well to illustrate the scope and relevance of the latter. With Porpora being a Marxist, I assume he refers to Marx's notion of exploitation. Consider what is involved. An emergent social totality that is a capitalist firm includes amongst its positioned components both workers and employers. Many of the rights (obligations) of the one are matched to the obligations (rights) of the other. Also amongst the various components of the firm is the labour power of each worker positioned as a commodity. Glossing over the details, Marx's idea is that under certain conditions typical to capitalist competition the wage paid by the employer to the worker to acquire her or his labour power for a given period of time (tending to its value or the amount required for the reproduction of a worker's labour power expended) is typically much less than the value derived from the expenditure of this labour power over the same period of time in producing the firm's products, and realised by selling these final products qua final commodities. Where, the value of (and so price received for) the products produced through the expenditure of labour power is greater than the value (or wages paid for the purchase) of the labour power expended, there is a surplus. The process just described whereby surplus is generated is, in Marx's terms, one of exploitation ${ }^{2}$. This is all part of the capitalist process as Marx theorised it, and the rights-obligation framework is essential to it.

Marx does not claim that surplus is produced without people accepting in the sense of consenting to what goes on. His theory of exploitation is not an arbitrary observation focussed upon highly contingent events or developments, somehow operating outside the prevailing position-rights-obligation framework. Rather, exploitation based on such a framework is a fundamental component of Marx's explanation of how the capitalist system functions. It is a system in which most individuals, because lacking (rights of ownership of) 
their own means of production, have no real option but to consent to being part of the process as positioned workers. Consent here means to accept being positioned as a wage-labourer under whatever conditions (rights-obligations relations) can best be achieved.

Porpora later quotes Lenin as saying that individuals enter relations without ever realising there is a social relation of production involved. But even if the category 'social relation of production' is not explicitly theorised by all participants in the relevant community, each must be aware at some level of her or his own positional rights and obligations, and implicitly thereby that others have obligations and rights that match them. Otherwise the system would not function at all. But these matched rights and obligations are indeed the relations of production. The features that likely are hidden from most of those involved in the labour process include the complex workings of the system as a whole, the totality that the positional social relations formed by matching rights and obligations, including fundamentally the relations of production, serve to organise.

Porpora's remaining two examples comprise inequality relations and conflicts of interest. But both are again all about rights and obligations. Barring a few chance events like winning a national lottery, the place of each individual in the structure of opportunities, including wages and other forms of income, depends on her or his (restricted) access to various positions, and the mechanisms in place for protecting or advancing rights associated with positions occupied (including income, benefits, bonus, overtime, paid/unpaid leave, ownership and hereditary, etc. rights,). The distribution of rights and obligations under capitalism underpins and grounds it all.

And major conflicts of interest most obviously arise precisely when individuals find themselves in various different positions simultaneously where the obligations of the different specific positions are in conflict (for example where a drugs prescribing GP is also 
positioned as member of a drugs company; or, say, a relative/partner of a job candidate is positioned on the appointments committee).

\section{Conflict in general}

Colin Wight too is concerned to emphasis alternative forms of social relation to those I prioritise. Wight's central criticism is seemingly that a rights and obligations framework is based only on cooperation and not conflict, so that it is conflictual relations I am unable to accommodate.

According to the conception I defend cooperation is indeed essential. But so too the potential for conflict (and not just conflicts of interest) is intimately involved; the two are not mutually exclusive (and trust and trustworthiness are essential in both cases). This is just because the exercising of a right by one individual means simultaneously getting at least one other individual, that bears a corresponding obligation, to act in ways that may be quite opposed to her or his actual desires. My faculty librarian (and in whom I trust and who is proving trustworthy in continuously cooperating) may yet be totally fed up with going to the library basement to retrieve books requested by me, and may even tell me so.

Nor need the conflict be of a mild or gentle sort. Police have rights to use violence, possibly even use guns, judges have the right to incarcerate people for life, others have the rights to issue fines, prohibit, sack, cut budgets, redistribute, detain, exclude, evict, and so on. In accepting the rights and obligations of community participation, we all of us accept (in the sense of go along with) the fact that rights (for some) of the sort just noted are part of the accepted organising structure of the relevant community.

Wight also looks to illegal forms of conflict, and so to the exercise of power through forms of behaviour that clash with accepted collective practices. Human trafficking is his central example. I am hardly going to deny such examples of power. But I do suggest that such examples presuppose the conception I defend, and are coherent qua illegal or 
illegitimate forms of practice only in relation to it (an illegitimacy that conditions the typically covert or related forms of behaviour frequently involved, and the responses to it). My concern though is with ontology. Forms of substantive practice clearly do vary according to whether or not they accord with community accepted structures. But the content of such practices are the concern of substantive science not ontology ${ }^{3}$; as far as I can see the ontological conception I defend remains relevant throughout.

Moreover, I suspect in any case that the more significant, because systematic and consequential, cases of illegal practice and such like, are not merely conditioned by the wider community structure of positions, rights and obligations, but are themselves coordinated through additional relational structures that conform to, and so illustrate, the ontological conception in question.

Consider again Wight's example of trafficking. As I understand it much of this is fairly large scale. If so, a good deal of complex co-ordination will be involved. As result, at least in such cases, I would expect the ontological conception I defend, if at all adequate, to provide the basic framework of which the trafficking organisation is seen to be a specific manifestation.

It seemingly does. For example, I note that a 2008 extensive working paper produced by The Vienna Forum to Fight Human Trafficking, presented at a UN sponsored workshop on Profiling the Trafficker ${ }^{4}$, reports that most trafficking organisations are structured as syndicates, ranging from family organisations to highly complex international organisations. Further, it finds that the practices of individual traffickers must be understood "in terms of their function in the hierarchy of roles in the trafficking organization or operation". In this regard, the report distinguishes positions of 'master trafficker', 'primary trafficker' (a position with numerous occupants; each of whom is charged with [accepts the obligation of] seeking to uncover sources of supply and demand, and do the buying and selling), 'secondary 
trafficker' (again a position with many occupants; the latter are responsible for delivering human cargo to primary traffickers); 'grassroots intelligence gatherer' (once more a position with many occupants; these are charged with seeking out vulnerable people); and so on. The authors report that right "throughout the process of trafficking, people (individual traffickers) are required to perform particular roles" as components of the organisation. Here, positions, and positioned rights and obligations are, as elsewhere, central to the functioning of the organisations in question.

In the context of discussing these issues Wight quotes me as arguing that in general: "In accepting (and being accepted) to be positioned as a member of a particular community, each individual makes a (usually merely implicit) commitment to conforming to the accepted collective practices of that community." Wight points out that this is not true for those trafficked. But of course, this is precisely because those being trafficked do not accept being positioned in this way. Even so, the substantive situation (once more a concern of substantive science rather than ontology) still relates back to the rights-obligation framework in that the trafficked, as with any prisoners, can be understood in terms of their having had most of their wider community rights forcibly (and in this case illegally) removed. Most associated practices (modes of resistance, methods of control, etc.) will follow from this feature of the situation.

\section{Complexity}

An additional charge that Wight introduces, this time under the theme of emergence, is that the specific relational conception I emphasise cannot deal adequately with forms of complexity. As a preliminary Wight rejects my use of the term 'emergence' and informs us that he confines its use to "the coming into being of a new level of life" 5 (Wight, 2016, p. 7). I see no good reason to do so. I find it potentially philosophically interesting to focus on any cases where novel causal powers come about, especially if they are irreducible to those of the 
elements when considered apart from any (equally emergent) organising structure. Of course, I do also apply the term to the coming into being of new levels, or better phenomena regarded as being at new levels. Indeed, I have traced the emergence of matter from quantum fields and their excitations though all the various 'levels' until we get the emergence of human beings, and through our interactions, the emergence of social reality (see e.g. Lawson 2012). In all this I argue that the revealed pattern is the emergence of totalities out of pre-existing phenomena that become organised as components. Of course the process is different in each case. That's why I think it is useful to use the term emergence interpreted as I do; it serves as a marker or a placeholder of where context-specific investigatory work has always to be done.

Such preliminaries aside, though, Wight's focus remains social relations. He informs us that communities have "differing sets of relations" (ibid, p. 8) to those based on rights and obligations, adding, strangely, that "rights and obligation[s] do not govern individuals as such, but rather they govern the relations between positioned actors.” (p. 8). This seems incoherent. Aside from the obvious point that rights and obligations can only directly influence conscious beings, sets of connecting rights and obligations are 'the relations between positioned actors'.

His main point, however, is that my framework, focussing on relations constituted by rights and obligations, is not appropriate to understanding either how different communities intra-relate to form a complex national state or whatever, or the natures of complex separate communities like the corporation.

But of course it is. To the contrary, it, or something very much like it, is essential to any such understanding however complexly interconnected or structured the particular communities may be. The various communities Wight lists (the military, political and cultural bodies, etc.) are precisely positioned as components of the wider totality that is a nation state, 
and thereby get to function to the benefit of the wider hosting community. In turn, of course, nation states may be positioned as components of wider regional communities or 'unions', accessing thereby their own union-specific rights and obligations ${ }^{6}$.

In his singling out the corporation as a feature that is challenging for the conception I defend to accommodate, I can only imagine that Wight fails to recognise that the very reason that all corporations, including local governments, schools, charities, and even (actually especially) the largest multinational business companies, are able to do as they do, and are as complex as they are, is precisely because they themselves are structured by (very particular) sets of positions and positional rights and obligations.

Each and every corporation, in fact, is constituted as such through of a process of (legal) positioning. More specifically, to be incorporated is to be accepted as an occupant of the position Judicial Person, a position nested within the wider position of Legal Person (the latter also nesting the position Natural Person, occupied by human beings) (see Lawson, 2015b). It is through this legal process of positioning that communities, thereby constituted as corporations, acquire legal capacity in the sense of gaining access, qua corporations, to rights and obligations intended originally only for human beings. Amongst the positioned rights so obtained are, first, those of ownership, including of other firms, and second, rights of limited liability if an owned firm get into difficulties. It is because of these two sets of rights especially that a multinational business corporation can create a multitude of subsidiaries, effectively own them, use them for multiple purposes including tax avoidance via transfer pricing, the relocating of any other liabilities, and even pursuing courses of profit seeking that contain a recognised potential (often realised) for wreaking damage and harm throughout the globe (see Lawson, 2015c), and yet, like any human shareholder, claim for itself (the right of) limited liability if any subsidiary winds up in trouble. None of this is comprehensible without the analytical framework of positions rights and obligations. The 
latter is not an optional add on, even less is it something without bearing, but is fundamental to everything about the corporation's (possibly complex) constitution and so basic activities (see Lawson, 2015b, 2015c).

\section{Reductionism}

Wight's final criticism of my particular relational focus takes the form of describing me as a methodological or ontological individualist. This move seems to be primarily 'justified' by the observation that my "social ontology contains individuals" (p.9) and also "communities, which are after all collections of individuals" (p. 9). Wight does acknowledge that I also posit numerous aspects of social structure, but supposes this hardly counts because such structure involves rights and obligations and "the causal force of rights and obligations can only manifest itself if individuals recognise them" (p. 9).

Of course, any community is not a mere collection of anything but rather comprises relationally organised individuals and other components; the relational structure is not an inconsequential or additive extra. But yes, individuals do need to be positioned and to recognise to a degree their positional rights and obligations, just in order to participate, and for the system to work at all. Positions with their rights and obligations are the site at which human beings and social structure interconnect. I do not suggest, of course, that because rights and obligations require some kind of recognition and representation, that individuals thereby fully or infallibly grasp thereby the prevailing conditions, the processes they are part of, or the functioning of other components and totalities that affect them. But they must grasp enough for themselves and the system successfully to function (where this occurs). The alternative stance is presumably that there is no such connection at all and that casual forces of the totality (and its structure) manifest themselves entirely without the participation of human individuals. This is methodological or ontological holism, perhaps Wight's position? 
But a form of individualism is not the only alternative; reductionism can, and ought, to be avoided altogether.

The key to it all, as I discuss at length elsewhere (see e.g., Lawson 2013, and my current reply to Searle) is indeed the contribution of social structure (including rights and obligations). The (emergent) causal powers of emergent totalities are brought to bear not without the participation of individuals (holism) and nor because of nothing but the participation of individuals (individualism) but through the relationally organised participation of positioned individuals (whatever the degree to which the latter fully comprehend the wider structures and totalities within which they are acting). It is just because emergent organising relational structures, turning fundamentally on positions and associated, to some extent necessarily-recognised, rights and obligations, have a causal impact on the actions of individual participants that both individualist and holist forms of reduction are untenable.

\section{Relations in general}

As Porpora's paper progresses it becomes increasing clear that those relations that he refers to as material, which he supposes cannot be accommodated by the conception I defend, are, in the main, not 'power-over' relations at all. Rather they are, or include, relations of comparison, order, temporality, fit, distance, correlation, etc., that can indeed hold 'objectively' without being recognised by community participants.

Porpora's illustrations include relations holding between various chess pieces that may be "independent of everyone's notice" (2016, p. 7), though understandably he focuses mostly on those that bear on human well-being. In this regard Porpora makes explicit reference to "the match between jobs and job-seekers; equality and inequality" (p. 8); mutual (related) threats; mutual benefits, perhaps arising unplanned from actions of seemingly separated individuals supposedly guided only by their equally separate individual interests ( $\mathrm{p}$. 
9) (presumably Porpora's interpretation of Smith's 'invisible hand'); and so on. Porpora refers to all such relations as ontologically objective; and he notes, quoting Lenin, that they are "those that take shape without passing through man's consciousness".

Here the topic is indeed relations that are somewhat different in nature to the matching rights/obligations I tend to emphasise. This brings me to the second line of response to the criticisms of Porpora and White, signalled at the outset.

Needless to say, I do not at all deny the fact of such relations. Why would I? Indeed, how could I? For amongst the basic ontological features that I have maintained throughout is a recognition that we human beings for the most part do not create social reality, but rather, on finding it given to us at each moment, each draw upon it in acting in always situated ways, pursuing our particular situated concerns, in conditions clearly not of our own making, with understandings that are always fallible and extremely partial at best, and in so doing thereby contribute, along with the simultaneous actions of all others, to the continuous reproduction and transformation of social reality in a manner that is mostly unintended and poorly understood (see e.g. Lawson, 1994, 1997, 2003, 2012, 2015). Indeed, this is a vision that I have continually elaborated as part of the project with which the three of us are involved. Given this, how could I possibly not accept or anticipate the fact of all sorts of contrasts and relations of quality and quantity, etc., including those emphasised by Porpora and Wight, that exist 'objectively' and are frequently unnoticed and even, in cases, perhaps beyond detection?

The contention I do maintain is not that the scope of social reality reduces to positions, rights and obligations, nor that relations of matching rights and obligations are the only kind to be found in the social realm, and nor even that they are the only 'power-over' form, but rather that a case can be made for regarding them as being, from a social ontological perspective, a fundamental, and perhaps the most fundamental, form of relation. For they are distinguished in being essential to the constitution of social reality, working at all 
levels to sustain a degree of continuity and stability despite social reality being everywhere processual in nature and conforming to the sketch of the preceding paragraph (see especially Lawson, 2016 on this). Let me elaborate this latter point a little as a way of concluding my response.

\section{Final comments}

The broad thesis I defend, already briefly touched upon, is that reality everywhere, from quantum fields to the social domain, consists of emergent totalities formed as organisations of pre-existing elements, with such emergent totalities themselves in turn becoming very often organised as components of higher level totalities (see e.g. Lawson, 2012).

In the process whereby pre-existing elements come to be organised as components of totalities the various sorts of elements involved have somehow to bind together. This may happen through processes of chemical bonding, electrical attraction, collision, etc., and in the cases of artefacts through the use of glue, nails, cement, and so on.

I have argued that the community, constituted through the organising of human beings amongst its components, is the most basic form of social totality (see e.g., Lawson 2012). In this context, and given that social phenomena are just as fluid as non-social phenomena, a central question clearly is what is it that binds together often disparate human individuals as components. My answer is that it is the positioning system, whereby individuals with the capacities both to trust and be trustworthy slot into community/system positions that are inter- and intra-related by way of positional rights and obligations. For the rights attached to one position match obligations somewhere and usually attached to different positions, and so serve to 'bind' together the relevant position occupants. In short, the positional rights/obligations relational framework is pivotal to the achieving of order and 
stability within a social world inevitably characterised by continuous transformation, and, as such, I suggest, warrants being recognised as ontologically rather fundamental. 


\section{References}

Lawson, T. (1994) A Realist Theory for Economics, in Backhouse, R. (ed.) New Directions in Economic Methodology, London and New York: Routledge, pp. 257-85.

Lawson, T. (1997) Economics and Reality, London and New York: Routledge. 34

Lawson, T. (2003) Reorienting Economics, London and New York: Routledge.

Lawson, T.(2012) Ontology and the study of social reality: emergence, organisation, community, power, social relations, corporations, artefacts and money, Cambridge Journal of Economics, vol. 36, no. 2, 345-85.

Lawson, T. (2013) Emergence, morphogenesis, causal reduction and downward causation, in Archer, M.S. (ed.), Social Morphogenesis, New York: Springer, pp. 61-84.

Lawson, T. (2015a) A Conception of Social Ontology, in Pratten, S. (ed.) (2015), pp. 19-52. Lawson, T. (2015b) The nature of the firm and peculiarities of the corporation, Cambridge Journal of Economics, 39, 1-32.

Lawson, T. (2015c). The modern corporation: the site of a mechanism (of global social change) that is out of control? forthcoming in Archer, M. S. (ed.), Social Morphogenesis: Generative Mechanisms Transforming the Social Order, New York, Springer.

Lawson, T. (2016). Collective Practices and Norms, in Archer, M. (ed.) (2016), Morphogenesis and Normativity, New York: Springer.

Porpora, D. (2016). Response to Tony Lawson: Sociology Versus Economics and Philosophy, Journal for the Theory of Social Behaviour (forthcoming).

Pratten, S. (ed.) (2015). Social Ontology and Modern Economics, London and New York: Routledge.

Wight, C. (2016). Over Socialising the Social World(s)?, Journal for the Theory of Social Behaviour (forthcoming). 


\section{Footnotes}

${ }^{1}$ For helpful comments on a first draft I am grateful to Jamie Morgan.

${ }^{2}$ With the degree of exploitation being the ratio of surplus-labour to necessary labour.

${ }^{3}$ Wight (2016, p. 7) actually wants me to "explain this phenomenon" of trafficking.

But, it is not the job of ontology to explain in the sense of identifying the reasons behind it or the substantive details of any mechanisms involved -- any more than it's the job of ontology to explain why I keep asking my faculty librarian to fetch certain books etc. Ontology can though help us understand the structures that render the practices mentioned feasible and intelligible, but the details in any case is down to substantive science.

${ }^{4}$ Produced under the auspices of the United Nations Initiative to Fight Human Trafficking, and downloaded on 14/04 2016 from https://www.unodc.org/documents/humantrafficking/2008/BP016ProfilingtheTraffickers.pdf

${ }^{5}$ Although it makes no difference to my response, I suspect Wight means new level of 'being' rather than 'life' here.

${ }^{6}$ In the case of membership of the European Union see e.g., the UK Government document "Rights and obligations of European Union membership" downloaded on April 27, 2016 from:

https://www.gov.uk/government/uploads/system/uploads/attachment_data/file/516501/Rights _and_obligations_of_European_Union_membership_web_version.pdf 